\title{
IN VIVO ANTITUMOR ACTIVITY OF PHYTOCHEMICAL PITC-2 OBTAINED FROM TISSUE CULTURED PLANT PLUCHEA INDICA ON SARCOMA-180 SOLID TUMOR MICE MODEL
}

\author{
SOUMITA GOSWAMI ${ }^{1}$, SOUVIK DEBNATH ${ }^{1}$, SAUMEN KARAN ${ }^{1}$, TAPAN KUMAR CHATTERJEE ${ }^{1,2 *}$
}

${ }^{1}$ Pharmacology Laboratory, Department of Pharmaceutical Technology, Jadavpur University, Kolkata - 700 032, West Bengal, India. ${ }^{2}$ Department of Pharmacy, JIS University, Agarpara, Kolkata - 700 109, West Bengal, India.

E mail: crctkc@gmail.com

Received: 28 November 2017, Revised and Accepted: 03 January 2018

ABSTRACT

Objective: PITC-2 was isolated from the methanolic root extract of tissue cultured medicinal plant Pluchea indica (L.) Less. PITC-2 is a thiophene derivative which is 2-(Prop-1-ynyl)-5(5,6-dihydroxyhexa-1,3-diynyl)-thiophene. The main objective of the study is to evaluate the in vivo antitumor activity of PITC 2 against sarcoma-180 cancer cell in Swiss albino mice.

Methods: The antitumor activity was evaluated by treatment with PITC-2 at a dose of 2.5 and 5 mg/kg b.w for 21 days on sarcoma-180 mice model.

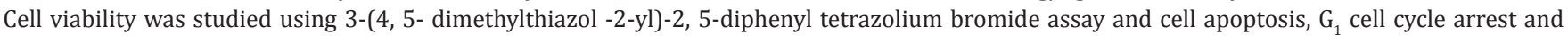
reduction in tumor cell proliferation were evaluated by histopathological analysis and Bcl-2, cyclic-D1, and Ki-67 protein expression through immunohistochemistry study.

Results: Precisely, PITC-2 had a cytotoxic effect on various in vitro cancer cells. Significant decreases in solid tumor volume and weight along with increase lifespan also observed. The histopathological and immunohistopathological examination indicates that PITC-2 induces apoptosis, typical morphological changes and suppresses tumor cell proliferation along with $G_{1}$ cell cycle arrest through the downregulation of the intratumoral expression of Bcl-2, cyclic D1, and Ki-67 and thus highlighting antiproliferative and apoptotic properties against sarcoma-180 in vivo solid tumor model.

Conclusion: The present results clearly demonstrate that PITC-2 significantly inhibits sarcoma-180 cell growth in a dose-dependent manner in in vivo mice model. Besides this, the study reveals a comprehensive perception of the possible mechanism behind the antitumor activity of PITC-2 by significant changes in the morphological, hematological, biochemical parameters in sarcoma-180 cells.

Keywords: Apoptosis, Cell viability, PITC-2, Sarcoma-180, Antitumor activity, Cell proliferation.

(C) 2018 The Authors. Published by Innovare Academic Sciences Pvt Ltd. This is an open access article under the CC BY license (http://creativecommons. org/licenses/by/4. 0/) DOI: http://dx.doi.org/10.22159/ajpcr.2018.v11i4.23968

\section{INTRODUCTION}

Cancer and tumors are considered as the most killer disease all over the world. Cancer is caused by abnormalities of the genetic material of the affected cells. Tumorigenesis is a multistep process that involves the accumulation of successive mutations in oncogenes and suppressor genes that deregulates the cell cycle. It is a cellular disease in which the normal relationship between epithelial cells and their underlying stomach cells are altered [1]. Tumor metastasis is responsible for approximately $90 \%$ of all cancer-related death [2]. Although struggling efforts against cancer have grown tremendously in past few years, still it is the second leading cause of death in economically developed countries. An increase in worldwide death rate was found on cancer patients which are 7.1 million and 8.2 million on 2007 and 2012, respectively [3,4]. By 2030 the global burden is expected to grow to 21.7 million new cancer cases and 13 million cancer death [5].

Cancer therapy is based on surgery, radiotherapy, and systemic chemotherapy. Chemotherapy induces apoptosis which initiates tumor cell death. Apoptosis is an evolutionarily conserved form of death of a cell to maintain tissue homeostasis which allows removal of damaged or superfluous cells. This can be mediated either by death receptor pathway or by mitochondrial pathway. First indication of apoptosis is activation of several caspases within the same cell and second evidence from different timing of caspase activation after addition of apoptotic stimuli are consistent with a hierarchy of caspase activation [6,7]. It is obvious that cancer chemotherapy is a very difficult task [8]. One of its main associated problems in the nonspecific toxicity of most anticancer drugs due to their biodistribution throughout the body, which requires the administration of a large total dose to achieve high local concentrations in a tumor. Another problem in cancer chemotherapy is drug resistance. It may be due to cancer cell mutation or by repairing the DNA breaks caused by anticancer drugs or by adopting some other mechanism that inactivates the drugs. Numerous cancer research studies have been conducted using traditional medicinal plants in an effort to discover new therapeutic agents that lack the toxic side effects associated with current chemotherapeutic agents [9]. Recent interest in these secondary metabolites has been focused on their medicinal properties [10]. In this project, we are using a tissue cultured plant Pluchea indica. The plant was tissue cultured with the purpose to obtain more secondary metabolites [11]. P. indica (L.) Less. is a species of flowering plant in the family Asteraceae. The terminal flowers are rose purple and grow in rather loose few-flowered heads. It is an evergreen large shrub found abundantly in salt marshes and mangrove swamps in Sunderbans (India), Bangladesh, Myanmar, China, Philippines, Malaysia, Tropical Asia, and Australia [12]. From the methanolic root extract of tissue cultured medicinal plant, $P$. indica PITC 2 was isolated. It is a thiophene derivative which is 2-(Prop-1-ynyl)-5(5,6-dihydroxyhexa-1,3-diynyl)thiophene. The main objective of the study was to evaluate the in vivo antitumor activity of PITC 2 against sarcoma-180 cancer cell in Swiss albino mice. 


\section{METHODS}

\section{Extraction and isolation}

The roots after being separated from the whole plant were washed and dried at $60^{\circ} \mathrm{C}$ in a forced air oven. Dried roots are grounded and extracted separately in petroleum ether $\left(60-80^{\circ} \mathrm{C}\right.$ for synthesis) and then dried and extracted in a Soxhlet extractor with methanol (AR grade, purity $99.8 \%$ ). After distillation of methanol, a sticky dark brown residue was obtained. For isolation of the phytochemical PITC 2 from tissue cultured plant Pluchea indica, the methanolic root extract was partitioned in a mixture of n-Butanol and water. From there butanol fraction was taken and then shacked with ethyl acetate to get an ethyl acetate soluble and insoluble part. Finally, ethyl acetate soluble part is taken and concentrated in a rotary vacuum evaporator and dried to obtain a crude residue which is then column chromatographed with a mixture of ethyl acetate and Petroleum ether. At a ratio 8:2 of pet ether and ethyl acetate from fraction 8-15 a prominent spot was observed in the thin-layer chromatography plate which is the desired phytochemical PITC-2 [2-(Prop-1-ynyl)-5(5,6-dihydroxyhexa-1,3diynyl)-thiophene] (Fig. 1). The presence of light yellow solid PITC-2 was further confirmed by testing the isolated compounds on nuclear magnetic resonance spectroscopy and MASS spectroscopy [13].

\section{Cell lines and cell culture}

In vitro cancer cell lines were obtained from National Centre for Cell Science, Pune, India, and Sarcoma-180 cancer cells were collected from Chittaranjan National Cancer Research Institute, Kolkata, India. The in vitro cells were maintained in Dulbecco's modified Eagle's medium, supplemented with $10 \% \mathrm{FBS}$ at $37^{\circ} \mathrm{C}$ in $\mathrm{CO}_{2}$ incubator in an atmosphere of humidified $5 \% \mathrm{CO}_{2}$ and $95 \%$ air. The cells were maintained by routine subculturing in tissue culture flasks. Tumor cell counts were done in a neubauer hemocytometer using the Trypan blue dye exclusion method. Cell viability was always found to be $95 \%$ or more.

Cytotoxicity assay (3-(4, 5- dimethylthiazol -2-yl)-2, 5-diphenyl tetrazolium bromide [MTT] assay)

This test is based on MTT, which is reduced to a purple-blue soluble formazan by the living cells [14]. Experiments were performed in 96-well flat-bottomed culture plates (BD Biosciences, USA). MTT was dissolved in phosphate buffered saline (PBS) at $5 \mathrm{mg} / \mathrm{ml}$. Different concentrations of PITC-2 $(0.1,0.5,01,5,10,20,25$, and $30 \mu \mathrm{g} / \mathrm{ml})$ were added and the plate was incubated for $24 \mathrm{~h}$. Following incubation with each compound for $24 \mathrm{~h}, 20 \mu \mathrm{L}$ of MTT was added to each well. After incubation for $4 \mathrm{~h}$ at $37^{\circ} \mathrm{C}$, the culture medium was removed, and the formazan crystals were dissolved in $200 \mu \mathrm{L}$ dimethyl sulfoxide (DMSO) [15]. Absorbance (A) of formazan dye was measured at $570 \mathrm{~nm}$ using a microplate reader. The background absorbance was determined at $690 \mathrm{~nm}$ and subtracted from the $570 \mathrm{~nm}$ measurement [2].

The percentage of viable cells was determined by the following equation: [16]

Viablecells $(\%)=\frac{\text { A of treatedcells }}{\text { A of untreatedcells }} \times 100$

The cytotoxic activities of this compound PITC- 2 were determined in human breast cancer cell MCF7, human lung cancer cell A549, human macrophage cell U937, and sarcoma S-180.

\section{Animals and study groups}

In vivo studies were carried out on female Swiss albino mice weighing $22 \pm 0.50 \mathrm{~g}$ of either. The animals were kept under standard conditions of 12:12 h light and dark cycle in polypropylene cages and fed with standard laboratory diet and water ad libitum. As the phytochemical PITC-2 was not freely soluble in water so $1 \%$, DMSO solution was prepared to make it solubilize. All in vivo experiments were conducted as per the guideline of Animal Ethics Committee of the Department of the Pharmaceutical Technology of Jadavpur University, India (Registration number: 147/1999/CPCSEA).

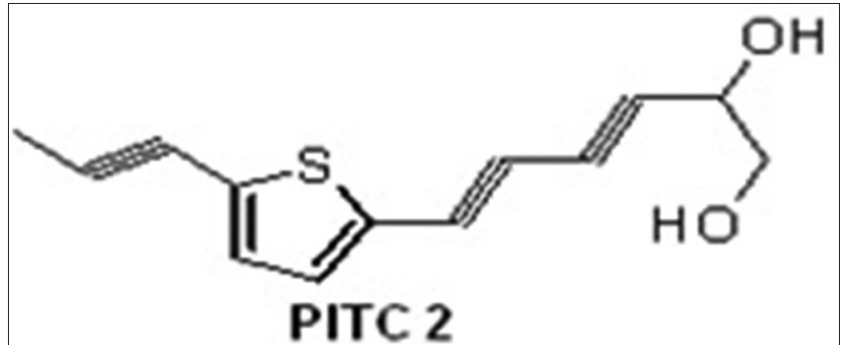

Fig. 1: 2-(Prop-1-ynyl)-5(5,6-dihydroxyhexa-1,3-diynyl)thiophene

For experimental purpose, animals are divided into five groups each containing 12 mice.

1. Group I: Normal animals (negative control).

2. Group II: Sarcoma cancer animals (positive control) $+1 \%$ DMSO $5 \mathrm{ml} / \mathrm{kg} /$ day.

3. Group III: Sarcoma cancer animals (test 1$)+$ PITC $2(2.5 \mathrm{mg} / \mathrm{kg} /$ day given orally).

4. Group IV: Sarcoma cancer animals (test 2)+PITC 2 (5 mg/kg/day given orally).

5. Group V: Sarcoma cancer animals (standard) $+5 \mathrm{FU}(20 \mathrm{mg} / \mathrm{kg}$ in alternative day given i.p).

Solid tumor induction by sarcoma 180 (S-180) cell line and experimental protocol

Sarcoma-180 cells were preserved in vivo in the peritoneal cavity of mice by intraperitoneal inoculation of cells in sterile normal saline [17]. Then, solid tumors were inoculated in the left hind leg of mice by intramuscular injection of S- 180 cells $\left(0.2 \mathrm{ml}\right.$ of $2 \times 10^{6}$ cells/mouse $)$ to all the groups' except the normal group [18]. Treatment was given from day 8 after inoculation of S-180 tumor for 21 days [19]. From each group, 6 mice were sacrificed, and other 6 were kept for calculation of mean survival time (MST).

Recording of survival rate

MST and percentage increase in lifespan (\%ILS) were calculated by the following formulas [20].

MST $=\frac{\sum \text { Survival time(day) of each mice in a group }}{\text { total number of mice }}$

$\%$ ILS $=\left[\frac{\text { MST of treated mice }}{\text { MST of control mice }} \times 100\right.$

\section{Tumor volume}

In case of solid tumor, tumor volumes were recorded using a vernier calipes and calculated as $\mathrm{V}\left(\mathrm{mm}^{3}\right)=\left(\mathrm{a}^{2} \times \mathrm{b}\right) / 2$ where a (smaller diameter) and $\mathrm{b}$ (large diameter) are perpendicular [21]. Tumor growth inhibition ratio was calculated as follows: Inhibition ratio $(\%)=([A-B] / A) \times 100$ where $\mathrm{A}$ is average tumor weight in negative control and $\mathrm{B}$ is average in each treatment group [22]. However, in case of an ascetic tumor, peritoneal fluid was collected from the peritoneal cavity. Then, the volume was measured by taking it in a graduated centrifuge tube.

\section{Hematological parameters}

Hematological studies were performed by recording the hemoglobin content, red blood cell (RBC), and white blood cells (WBC) counts from freely flowing tail vein blood [23]. Differential WBC leukocyte counts were carried out including neutrophils, lymphocytes, and monocytes from Leishman stained blood smears of normal, sarcoma-180 control and PITC 2 treated groups, respectively.

\section{Biochemical parameters}

After $24 \mathrm{~h}$ of last dose and $18 \mathrm{~h}$ of fasting the blood sample were collected by puncturing retro-orbital plexus. Blood was used for the assay of biochemical 
parameters serum glutamate oxaloacetate transaminase (SGOT), serum glutamate pyruvate transaminase (SGPT), albumin, globulin, bilirubin, alkaline phosphatase (ALP), and serum protein to investigate liver function alteration and creatinine was measured as a renal function parameter

\section{Histopathology}

The tumor, liver and kidney were excised and fixed in $10 \%$ buffered formalin and embedded in paraffin. $+5-\mu \mathrm{m}$ sectioned was stained with hematoxylin and eosin (H and E) [24]. Histological analysis was performed under a light microscope (40x). The morphological changes were photographed and there compared.

Immunohistochemical analysis of Bcl-2, Ki-67, cyclin-D1

Tumor section was deparaffinized with xylene and dehydrated with ethanol. After blocking the slides with $5 \%$ bovine serum albumin in Tris-buffered saline, the sections were then stained with a primary antibody specific to Bcl-2, Ki-67, and cyclin-D1, at a concentration of $1 \mu \mathrm{g} / \mathrm{ml}$ at $4^{\circ} \mathrm{C}$ overnight, followed by mouse monoclonal antibody. After washing sections with PBS, they were incubated with diaminobenzidine substrate and counterstained with Mayer's hematoxylin. Then, they were visualized in a digital camera installed on a light microscope $[2,21]$.

\section{Statistical analysis}

For cytotoxicity studies, the confidence interval (IC I $_{50}$ ) values and 95\% CI were obtained by nonlinear regression. All in vitro studies were carried out in triplicate represented by independent biological evaluation. Data are extracted as a mean \pm standard error of the mean and were compared by one-way analysis of variance followed by Kruskal-Wallis test using SPSS statistical software of 20.0 version. $\mathrm{p}<0.05$ was considered to be statistically significant when compared with control.

\section{RESULTS}

\section{In vitro cell viability assay}

The phytochemical PITC 2 was screened for its cytotoxicity against human breast cancer cell MCF7, human lung cancer cell A549, human macrophage cell U937, and sarcoma S-180 at different concentrations $(0.1,0.5,01,5,10,20,25$, and $30 \mu \mathrm{g} / \mathrm{ml})$ to determine the percentage of viable cells by MTT assay. MTT assay shows a significant effect on sarcoma S-180, MCF-7, A-549, and U-937 cancer cells (Fig. 2). This result indicates antiproliferative activity of PITC-2 in cancer cells. Among these cancer cells, PITC-2 is most potent for U-937 cells.

\section{Inhibition of Sarcoma-180 solid tumor growth by PITC-2}

PITC-2 at concentrations $2.5 \mathrm{mg} / \mathrm{kg}$ and $5 \mathrm{mg} / \mathrm{kg}$ shows a good reduction of solid tumor volume and weight at the end of 21 days compared to that of control group mice. PITC-2 treated groups also shows significant reduction of body weight (Fig. 3 and Table 1).

\section{PITC-2 enhanced survival of sarcoma 180 bearing mice}

As shown in Table 1 and Kaplan-Meier survival curve (Fig. 4a) a significant increase in survival time and lifespan of sarcoma-180 bearing mice treated with PITC- 2 was found in comparison with sarcoma bearing control group. The \%ILS was found to be dosedependent (Fig. 4b).

\section{Effect of PITC-2 on hematological parameters}

An increase in hemoglobin level, RBC count, neutrophil level and decrease in WBC level, monocyte, and lymphocyte count was found in PITC 2 treated groups in a dose-dependent manner in compared to that of sarcoma-180 control group (Table 2).

\section{Effect of PITC-2 on biochemical parameters}

PITC-2 treated group's shows a significant decrease in SGPT, SGOT, and serum ALP parameters are found in a dose-dependent manner (2.5 and $5 \mathrm{mg} / \mathrm{kg}$ b.w) in comparison with sarcoma-180 control group. A dosedependent increase in total protein was also found (Table 3).

\section{Histopathology of liver and kidney tissue}

Fig. 5a shows $\mathrm{H}$ and $\mathrm{E}$ stained section of liver of healthy mice which bears all the normal features, including circular hepatic portal vein and

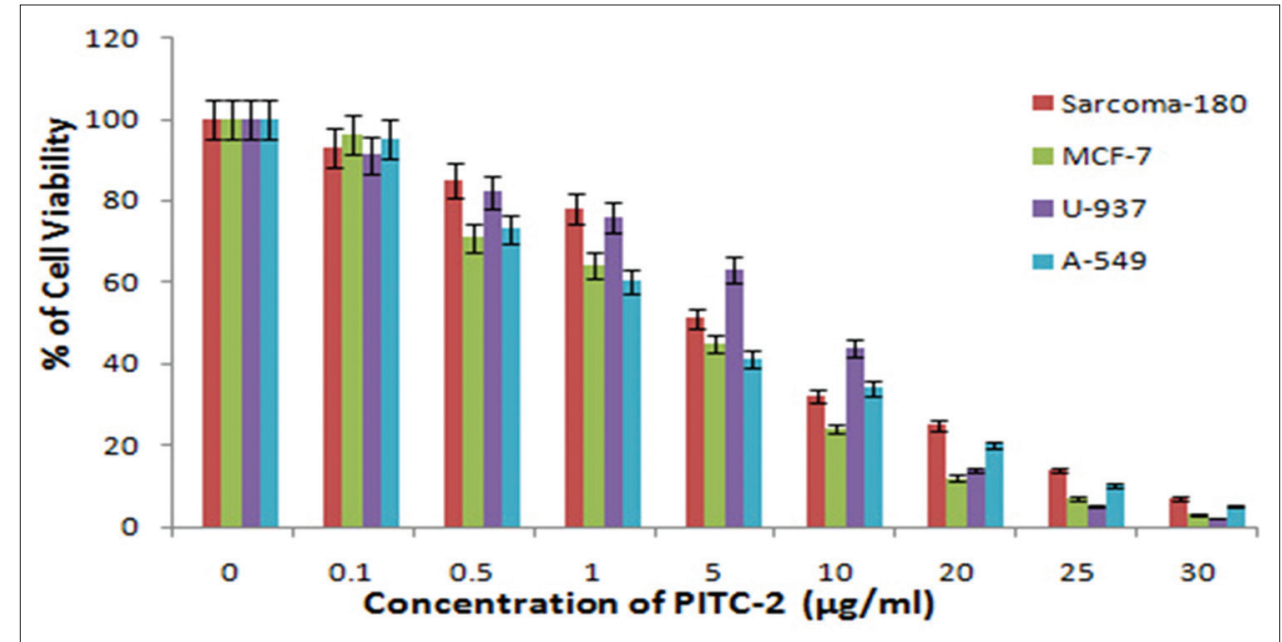

Fig. 2: In vitro cytotoxic activity of PITC-2 against Sarcoma 180, MCF-7, U-937, and A-549. Values are expressed as mean \pm standard deviation

Table 1: In vivo effect of PITC-2 on solid tumors and study groups

\begin{tabular}{lllll}
\hline Parameters & PITC-2 2.5 mg/kg b.w & PITC-2 5 mg/kg b.w & Standard drug 5-FU 20 mg/kg b.w & Sarcoma-180 control \\
\hline Tumor weight $(\mathrm{g})$ & $1.156 \pm 0.03^{*}$ & $0.649 \pm 0.008^{*}$ & $0.890 \pm 0.03^{*}$ & $3.90 \pm 0.11^{*}$ \\
Tumor volume $\left(\mathrm{mm}^{3}\right)$ & $1900.75 \pm 45.30$ & $1563.10 \pm 27.65$ & $1823.64 \pm 33.73$ & $6642.30 \pm 51.34$ \\
Tumor inhibition ratio \% & $71.38 \pm 1.72^{*}$ & $76.46 \pm 0.27^{*}$ & $72.54 \pm 0.96^{*}$ & $0 \pm 0$ \\
Body weight $(\mathrm{g})$ & $24.05 \pm 0.43^{*}$ & $22.71 \pm 0.42^{*}$ & $23.68 \pm 0.55^{*}$ & $27.10 \pm 0.48^{*}$ \\
MST (days) & $34.67 \pm 0.98^{*}$ & $52.83 \pm 0.70^{*}$ & $42.00 \pm 0.85^{*}$ & $19.50 \pm 0.42^{*}$ \\
\%ILS & 77.79 & 170.92 & 115.38 & $0 \pm 0$ \\
\hline
\end{tabular}

*<0.05 as compared to control group ( $\mathrm{n}=6$ mice per group). ILS: Increase in lifespan, MST: Mean survival time 
Table 2: Effect of PITC-2 on hematological parameters in sarcoma-180 solid tumors bearing mice

\begin{tabular}{|c|c|c|c|c|c|}
\hline Parameters & $\begin{array}{l}\text { PITC-2 } \\
2.5 \mathrm{mg} / \mathrm{kg} \mathrm{b.w}\end{array}$ & $\begin{array}{l}\text { PITC-2 } 5 \\
\text { mg/kg b.w }\end{array}$ & $\begin{array}{l}\text { Std 5-FU } \\
20 \mathrm{mg} / \mathrm{kg} \mathrm{b.w}\end{array}$ & $\begin{array}{l}\text { Sarcoma-180 } \\
\text { control }\end{array}$ & Normal mice \\
\hline Hemoglobin (g/dl) & $7.5 \pm 0.05^{*}$ & $10.4 \pm 0.03^{*}$ & $8.5 \pm 0.08^{*}$ & $6.3 \pm 0.01 *$ & $12.8 \pm 0.12^{*}$ \\
\hline Erythrocyte (RBC) (cells $\times 10^{6} / \mathrm{mm}^{3}$ ) & $4.34 \pm 0.04 *$ & $6.53 \pm 0.02^{*}$ & $5.6 \pm 0.03^{*}$ & $3.75 \pm 0.04^{*}$ & $7.90 \pm 0.02 *$ \\
\hline Leukocytes (WBC) $\left(\right.$ cells $\left.\times 10^{6} / \mathrm{mm}^{3}\right)$ & $14.1 \pm 0.05^{*}$ & $10.19 \pm 0.05^{*}$ & $4.29 \pm 0.05^{*}$ & $16.69 \pm 0.02 *$ & $6.40 \pm 0.03^{*}$ \\
\hline Neutrophil (\%) & $42.3 \pm 0.03^{*}$ & $39.46 \pm 0.03^{*}$ & $30.1 \pm 0.02 *$ & $68.5 \pm 0.05^{*}$ & $19.4 \pm 0.03^{*}$ \\
\hline Lymphocyte (\%) & $48.0 \pm 0.04^{*}$ & $51.0 \pm 0.04^{*}$ & $63.0 \pm 0.09 *$ & $35.8 \pm 0.11^{*}$ & $64.1 \pm 0.23^{*}$ \\
\hline Monocyte (\%) & $1.5 \pm 0.03^{*}$ & $1.4 \pm 0.03^{*}$ & $1.7 \pm 0.03^{*}$ & $1.3 \pm 0.04^{*}$ & $2.8 \pm 0.01^{*}$ \\
\hline
\end{tabular}

$*<0.05$ as compared to control group ( $\mathrm{n}=6$ mice per group). RBC: Red blood cell, WBC: White blood cells

Table 3: Effect of PITC-2 on biochemical parameters in sarcoma-180 solid tumors bearing mice

\begin{tabular}{|c|c|c|c|c|c|}
\hline Parameters & $\begin{array}{l}\text { PITC-2 } \\
2.5 \mathrm{mg} / \mathrm{kg} \text { b.w }\end{array}$ & $\begin{array}{l}\text { PITC-2 } \\
2.5 \mathrm{mg} / \mathrm{kg} \mathrm{b.w}\end{array}$ & $\begin{array}{l}\text { Standard 5-FU } \\
20 \mathrm{mg} / \mathrm{kg} \mathrm{b.w}\end{array}$ & $\begin{array}{l}\text { Sarcoma } 180 \\
\text { control }\end{array}$ & Normal mice \\
\hline Bilirubin (total) mg/dl & $0.20 \pm 0.02^{*}$ & $0.26 \pm 0.02 *$ & $0.29 \pm 0.03^{*}$ & $0.34 \pm 0.01^{*}$ & $0.4 \pm 0.02 *$ \\
\hline Serum protein (total) g/dl & $8.12 \pm 0.09 *$ & $9.69 \pm 0.07^{*}$ & $5.22 \pm 0.12^{*}$ & $15.4 \pm 0.08 *$ & $8.19 \pm 0.08^{*}$ \\
\hline AST (SGOT) U/L & $0.71 \pm 0.01^{*}$ & $0.60 \pm 0.01^{*}$ & $0.59 \pm 0.01^{*}$ & $0.6 \pm 0.09 *$ & $0.8 \pm 0.01^{*}$ \\
\hline ALT (SGPT) U/L & $351 \pm 0.04^{*}$ & $175 \pm 0.01^{*}$ & $178 \pm 0.06^{*}$ & $199 \pm 0.07 *$ & $414 \pm 0.04^{*}$ \\
\hline Serum ALP U/L & $73 \pm 0.02^{*}$ & $68 \pm 0.02^{*}$ & $18 \pm 0.05^{*}$ & $40 \pm 0.03^{*}$ & $74 \pm 0.03^{*}$ \\
\hline Creatinine $\mathrm{Mg} / \mathrm{dl}$ & $1 \pm 0.01 *$ & $1 \pm 0.01^{*}$ & $1 \pm 0.01^{*}$ & $1 \pm 0.02 *$ & $1 \pm 0.01^{*}$ \\
\hline
\end{tabular}

$*<0.05$ as compared to control group ( $n=6$ mice per group). AST: Aspartate aminotransferase, ALT: Alanine aminotransferase, ALP: Alkaline phosphatase, SGOT: Serum glutamate oxaloacetate transaminase, SGPT: Serum glutamate pyruvate transaminase

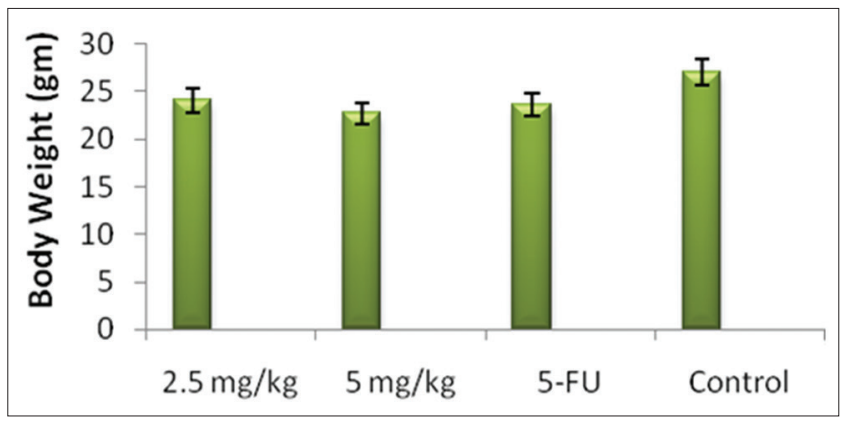

Fig. 3: Effect of PITC-2 treatment on body weight

of hepatic artery, as marked by arrow. It shows prominent nuclei, and the tissue section comprises hepatic sinusoid which is usual. However, in case of the Sarcoma-180 control group showed in Fig. 5b none of the above-mentioned regular features are observed, rather it shows extreme hepatocellular lesions as pyknotic nuclei, exhibiting necrotic hepatocytes. Group receiving standard 5-FU shows a lesser amount of hepatocellular lesion, which is close to normal as shown in Fig. 5c. Although little changes are found such as deformed hepatic artery and irregular bile duct. Groups receiving a different dose of PITC-2 also show a little hepatic deformation and altered hepatocyte population shown in Fig. $5 d$ and e. Healthy hepatocytes were observed, regular branch of bile duct found, although mild dilation of central vein observed.

Fig. 6a shows $\mathrm{H}$ and $\mathrm{E}$ stained section of kidney of a healthy mice which bears all the normal features, while sarcoma-180 control group showed in Fig. 6b show severe glomerular and tubular hemorrhage with increase swelling of tubular epithelium and presence of hyaline cylinders. Group treated with 5-FU and PITC-2 shows cellular features which have less deformation and close to normal in Fig. 6c-e, respectively, with light glomerular and tubular hemorrhage.

\section{Histopathological changes of solid sarcoma-180 tumor}

Histopathological examination of solid sarcoma-180 tumor control group shows intact anaplastic cancer cells with areas of necrosis and focal hemorrhage reflecting viability and aggressiveness of tumor (Fig. 7a). It shows sheets of large rounded and polygonal cells with hyperchromatic nuclear and binucleation. Whereas solid tumor of group treated with 5-FU (Fig. 7b) and PITC-2 with different doses
(2.5 mg/kg and $5 \mathrm{mg} / \mathrm{kg}$ ) (Fig. 7c and d) shows areas of necrosis. Low cell proliferation and muscle invasion were found, and with an increase in dose, tumor cells lose their details and architecture.

Immunohistochemical analysis of Bcl-2, Ki-67, and cyclin-D1

The tumor cells were considered positive Bcl-2, Ki-67, and cyclic-D1 with the presence of yellow-brown nuclear staining in Ki-67 (Fig. 8) and greenish brown nuclear staining in Bcl-2 (Fig. 9) and cyclic-D1 (Fig. 10). Here we are studying the regression in tumor growth by PITC2 , due to apoptosis that decreases expression of antiapoptotic protein Bcl-2, G1 cell cycle arrest by suppression of cyclic-D1 cell cycle protein. Futhermore, PITC-2 reduces tumor cell proliferation by decreasing Ki67 tumor proliferation protein. A significant decrease in positive Bcl-2, Ki-67, and cyclic-D1 were found in PITC-2 treated group, compared to that of sarcoma-180 control group was observed which shows effective suppression of tumor. Meanwhile, it was found that the decrease in protein expression is dose-dependent and is better in case of PITC-2 with dose $5 \mathrm{mg} / \mathrm{kg}$ b.w.

\section{DISCUSSION}

Cancer is a group of disease which involves abnormal growth of cell which is rapid and uncontrolled with the potential to spread in other parts of the body. Anticancer drugs or antineoplastic drugs are drugs effective in the treatment of a malignant disease which trigger signaling mechanism that initiates apoptosis or cell death [25]. At present, available synthetic drugs have many adverse reactions which can be minimized to a great extent by the natural compound. The aim of the study was to evaluate the in vivo antitumor activity of PITC-2 against sarcoma-180 cancer cell in Swiss albino mice. Therefore, we established a mouse model bearing sarcoma-180 to study the antitumor activity of the drug. The mice treated with PITC- 2 at different dose inhibit body weight, tumor weight, tumor volume, tumor inhibition ratio and also brought hematological parameters to more or less normal level which is dose-dependent. A same type of finding was observed by de Costa et al. on in vivo anticancer and antiangiogenic potential of thalidomide derivatives [22]. This study also shows inhibition of body weight, tumor volume, and tumor inhibition ratio. A good ILS and survival time was also noted in sarcoma-180 solid tumor-bearing mice when treated with PITC-2. A major problem in cancer chemotherapy is myelosuppression and anemia. Tumor-bearing mice have anemia mostly due to a reduction in $\mathrm{RBC}$ or low hemoglobin percentage. This may occur due to iron deficiency or due to myelopathy condition [23]. Treatment with 


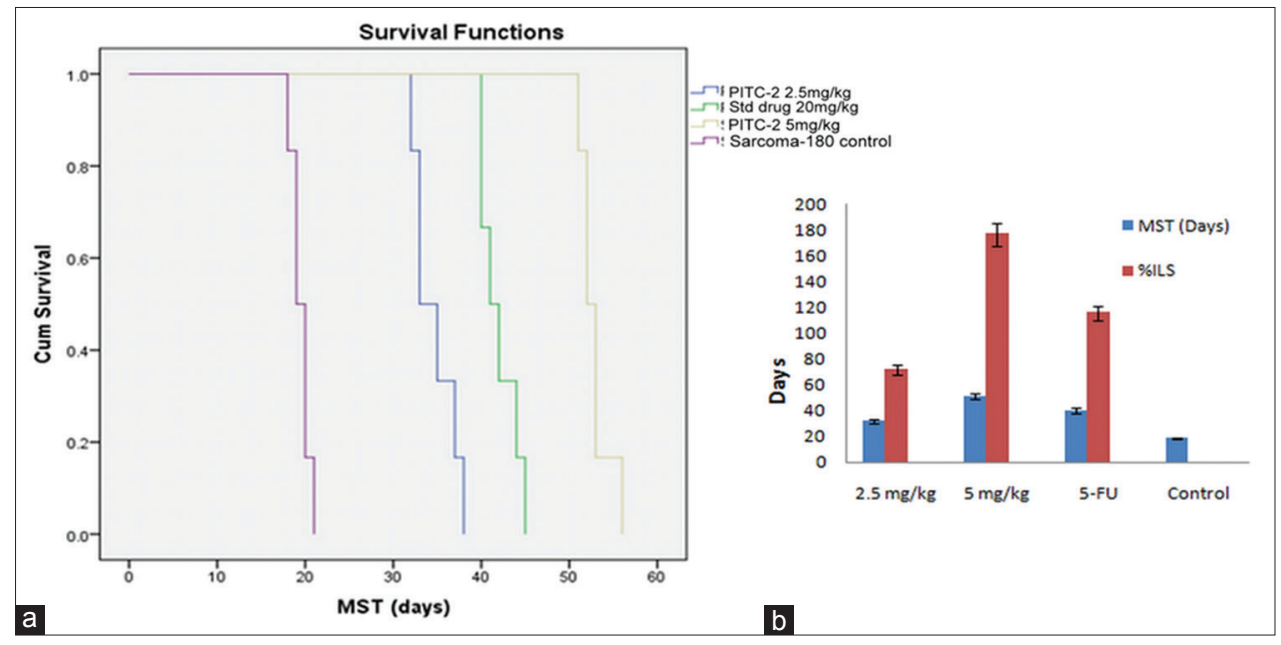

Fig. 4: (a) Kaplan-Meier survival curve showing survival of all groups, (b) effect of PITC-2 treatment on mean survival time, and percentage of increase lifespan

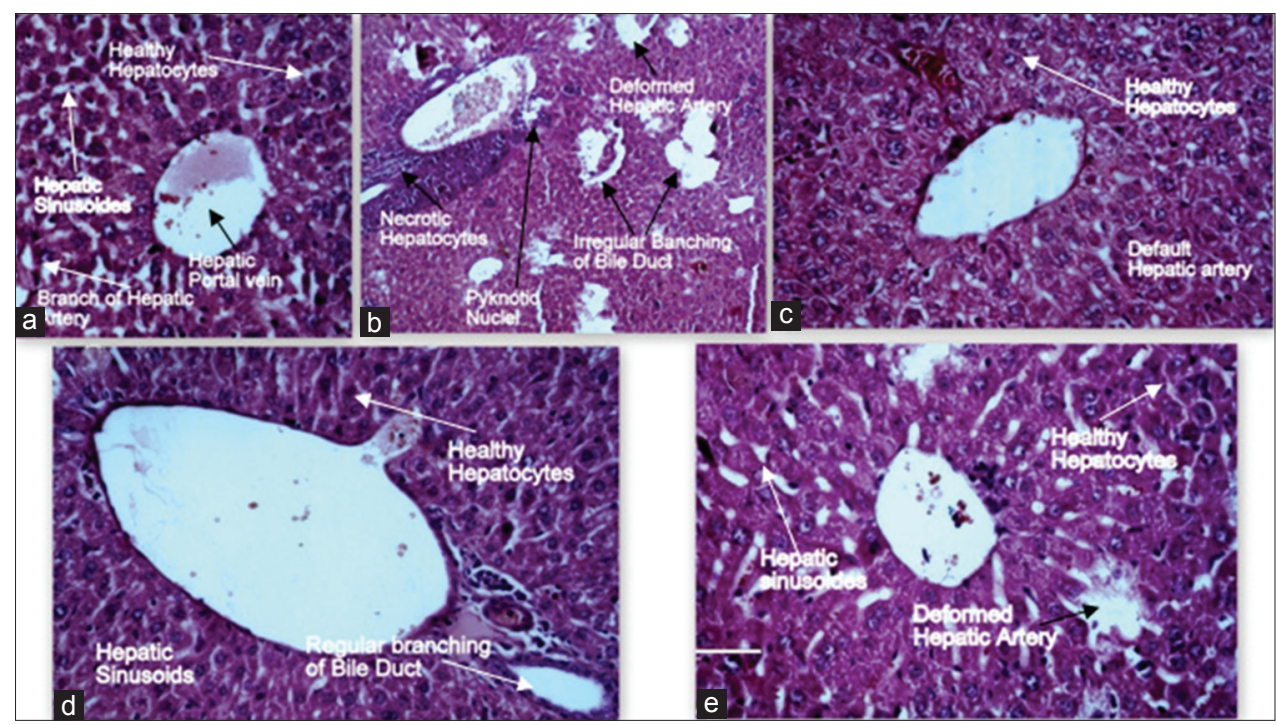

Fig. 5: Hematoxylin and eosin stained section of mice liver showing cellular changes for (a) normal healthy mice, (b) sarcoma-180 control group, (c) standard 5-FU treated group, (d) $2.5 \mathrm{mg} / \mathrm{kg}$ of PITC-2, and (e) $5 \mathrm{mg} / \mathrm{kg}$ of PITC-2 (magnification 40×)

PITC-2 stabilizes hemoglobin concentration, RBC and WBC cell count near to normal value. This reveals the protective activity of PITC- 2 on the hematopoietic system. Another problem of cancer chemotherapy is liver toxicity which is due to accumulation of drug metabolites in liver [26]. In this study, liver toxicity was analyzed by biochemical studies and histopathology of liver tissue. Aspartate aminotransferase (AST), alanine aminotransferase (ALT), and ALP levels of control group mice, normal mice, and drug-treated mice were compared, and it was found that PITC-2 treated mice had less toxic liver than others as the level of AST, ALT, and ALP are close to normal value. These all features such as decrease in body weight, tumor weight, tumor volume, ILS and survival time, stabilizing hematological, and biochemical parameters of PITC-2 are dose-dependent, that in stabilizing effects are better in animals treated with higher dose of PITC-2. These features help in judging the drug activity.

Histopathological analysis of kidney for control, 5-FU, and PITC2 for different dose was done. It was found that several degrees of hydropic changes of proximal tubular epithelium, glomerular, and tubular hemorrhage. These findings were much more prominent in control group animal than drug-treated groups where these effects are low, but the glomeruli structures were essentially preserved. The necrosis is characterized by no nuclear staining and deeply eosinophilic cytoplasm [27]. This show PITC-2 is less toxic to kidney than standard drug. Many drugs can cause lesion of liver found on biopsy. A large number of drugs with different pharmacological action and chemical structure give rise to liver lesion. Although liver shows a great adaptive and regenerative ability, for example, if anticonvulsant drugs are used for a long time, it causes an increase in endoplasmic reticulum which is regarded as an adaptive phenomenon. Again regeneration of hepatic tissue occurs by the conjugative tissues after hepatocellular necrosis due to treatment with alginates [27]. In our study, normal healthy mice show prominent nuclei and the tissue section comprises hepatic sinusoid which is usual. However, in case of sarcoma- 180 control group none of the above mentioned regular features are observed, rather it shows extreme hepatocellular lesions as pyknotic nuclei, exhibiting necrotic hepatocytes. Group receiving a different dose of PITC-2 are close to normal although little changes are found such as deformed hepatic artery and irregular bile duct which show PITC-2 is less toxic to liver.

From MTT assay it was found that PITC-2 has notable in vitro cytotoxic effect on S-180, MCF-7, A-549, and U-937 cancer cells. The mechanism of apoptosis is its diverse alteration of cells. Hence, cell apoptosis 


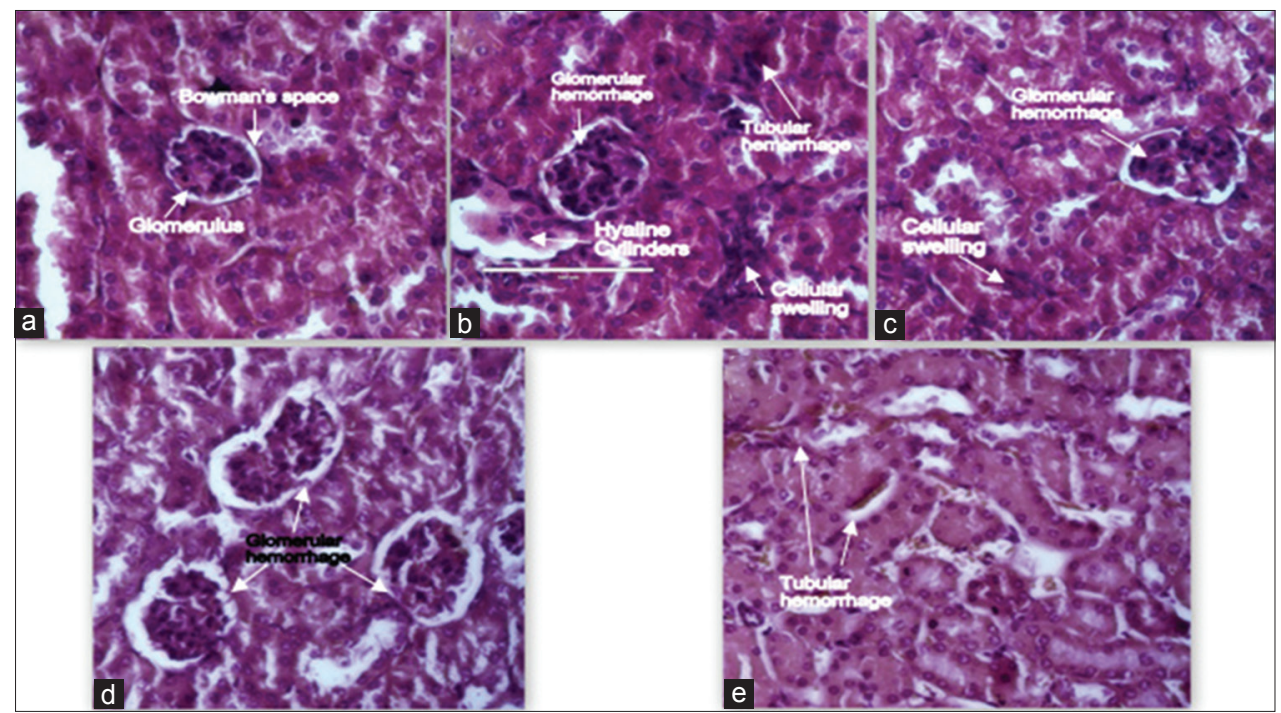

Fig. 6: Hematoxylin and eosin stained section of mice kidney for (a) normal healthy mice, (b) sarcoma-180 control group, (c) standard 5-FU treated group, (d) $2.5 \mathrm{mg} / \mathrm{kg}$ of PITC-2, and (e) $5 \mathrm{mg} / \mathrm{kg}$ of PITC-2 (magnification 40×)

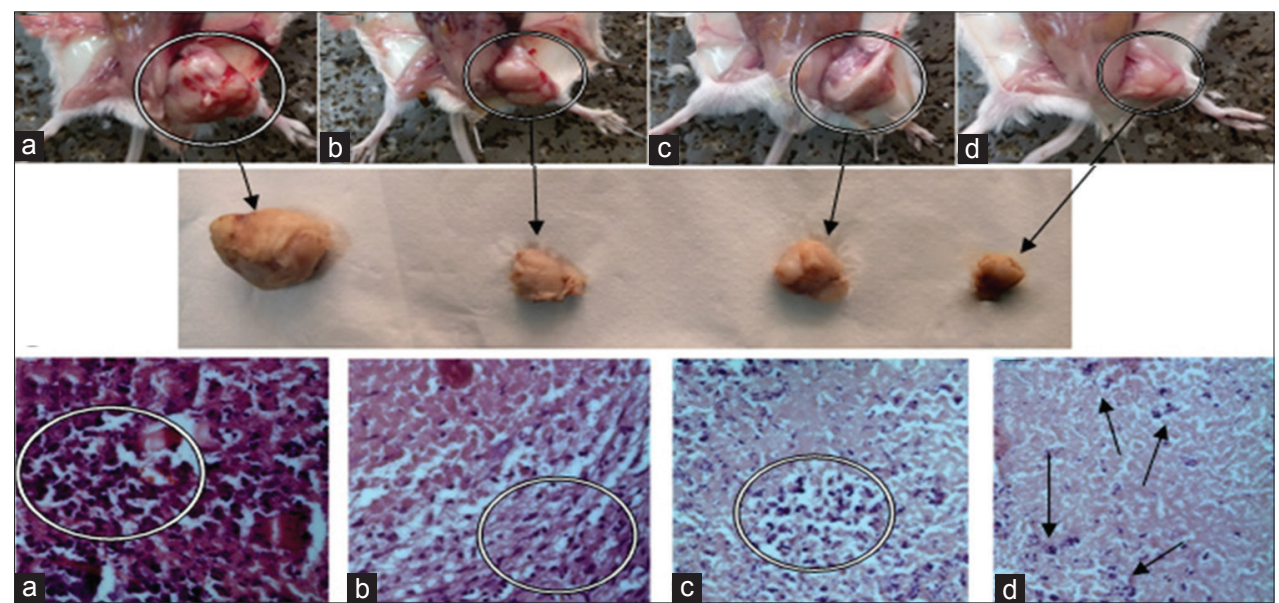

Fig. 7: Effect of PITC-2 treatment on solid sarcoma-180 tumor: (a) Sarcoma-180 control group, (b) standard 5-FU treated group, (c) $2.5 \mathrm{mg} / \mathrm{kg}$ of PITC-2, (d) $5 \mathrm{mg} / \mathrm{kg}$ of PITC-2, panel (1) shows tumor growth on animals, panel (2) shows tumor isolated from animal body, panel (3) hematoxylin and eosin stained histological section of solid tumor (magnification 40x). The cellular features are marked by circle

is identified by antiapoptotic protein Bcl-2 [28,29]. Bcl-2 plays an important role in apoptosis regulation in physiological and pathological conditions. Prevention of the loss of mitochondrial membrane potential is one of its notable works. It also prevents the release of cytochrome c into the cytosol which activates caspases by the mitochondrial pathway. Overexpression of Bcl-2 inhibits caspase-3 activation [30,26]. In our study, it was found that after treatment with PITC-2 on sarcoma-180 cells a significant decrease in Bcl-2 was observed whereas an increase in level Bcl-2 was observed in control group animals. This result concludes that increase of $\mathrm{Bcl}-2$ would be a cellular response to counteract the apoptosis which is already initiated. Therefore, PITC-2 reduces the ability of $\mathrm{Bcl}-2$ expression and initiates apoptosis.

To identify the tumor proliferation rate the cells, tumor cells are stained with Ki67. Nuclear staining was observed in all tumor sections which are immunized with Ki67 antibody. Mouse monoclonal antibody of Ki67 was used that identifies a nuclear antigen associated with G1, S, G2, and $M$ phase. The expression of this molecule is found in all cell cycle except in G0 and early G1 phase [31]. In our study, it was found that a decrease in positive Ki67 cells in animals treated with $5 \mathrm{FU}$ and PITC-2 when compared to control group. It was also noted that reduction in tumor proliferation rate is more for a higher dose of PITC-2.

Cyclic D1 overexpression is an indication of early cancer onset and tumor progression [32]. Cyclic D1 is a protein required for progression through G1 phase during the cell cycle. It synthesizes rapidly during G1 phase and accumulates in the nucleus. Further, it starts degrading when it enters $\mathrm{S}$ phase [33]. Our study shows a marked decrease in expression of Cyclic D1 in animals treated with 5FU and PITC-2 when compared to control group. Even more effective result was shown by a different dose of PITC-2 than 5FU which reveals antitumor activity PITC-2.

\section{CONCLUSION}

The present results clearly demonstrate that PITC-2 significantly inhibits sarcoma-180 cell growth in a dose-dependent manner in in vivo mice model. Besides this, the study reveals a comprehensive perception of the possible mechanism behind the antitumor activity of PITC-2 by significant changes in the morphological, hematological, and biochemical parameters in sarcoma-180 cells. Moreover, the histopathological and immunohistopathological examination indicates that PITC-2 induces apoptosis and suppresses tumor cell proliferation along with G1 cell 


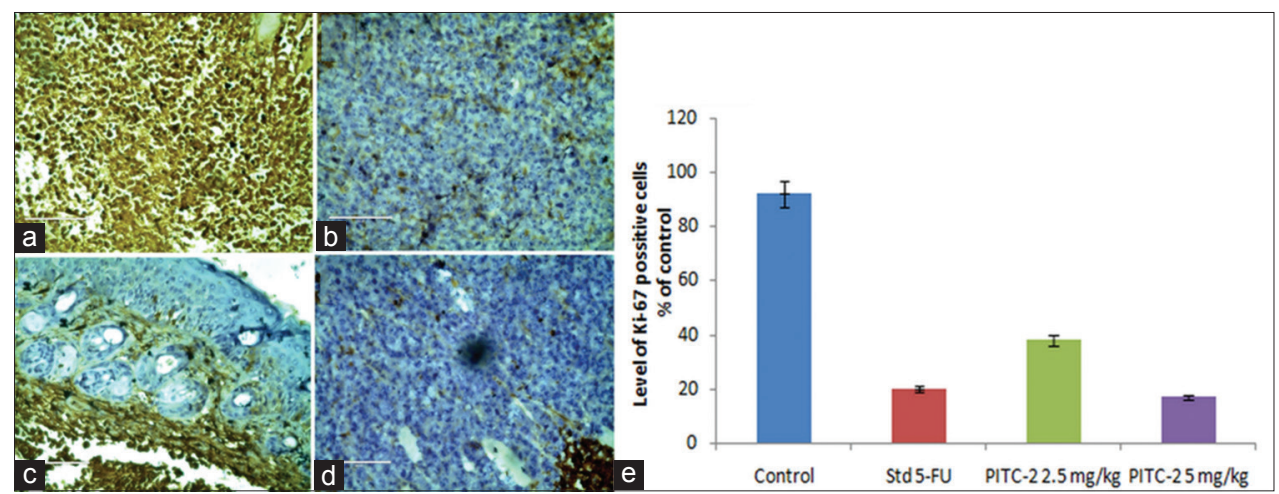

Fig. 8: (a) Sarcoma-180 control, (b) standard 5-FU, (c) PITC-2 $2.5 \mathrm{mg} / \mathrm{kg}$, and (d) PITC-2 $5 \mathrm{mg} / \mathrm{kg}$ shows Ki67 expression (magnification 40x). (e) Shows level of immunopositive Ki67 cells, values are given in mean \pm standard deviation

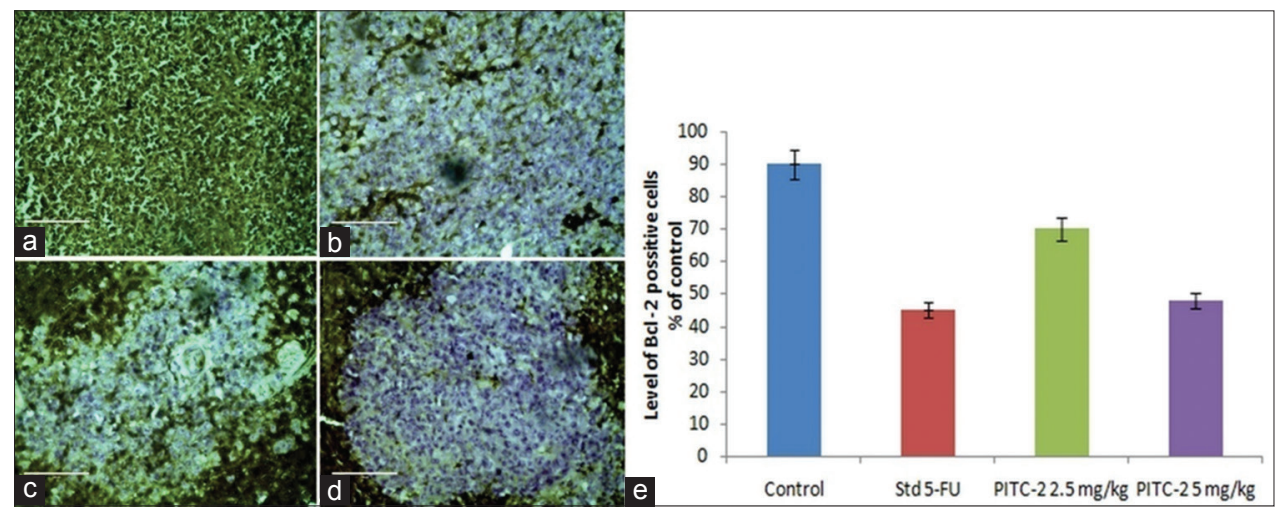

Fig. 9: (a) Sarcoma-180 control, (b) standard 5-FU, (c) PITC-2 $2.5 \mathrm{mg} / \mathrm{kg}$, and (d) PITC-2 $5 \mathrm{mg} / \mathrm{kg}$ shows Bcl-2 expression (magnification 40x). (e) Shows level of immunopositive Bcl-2 cells, values are given in mean \pm standard deviation

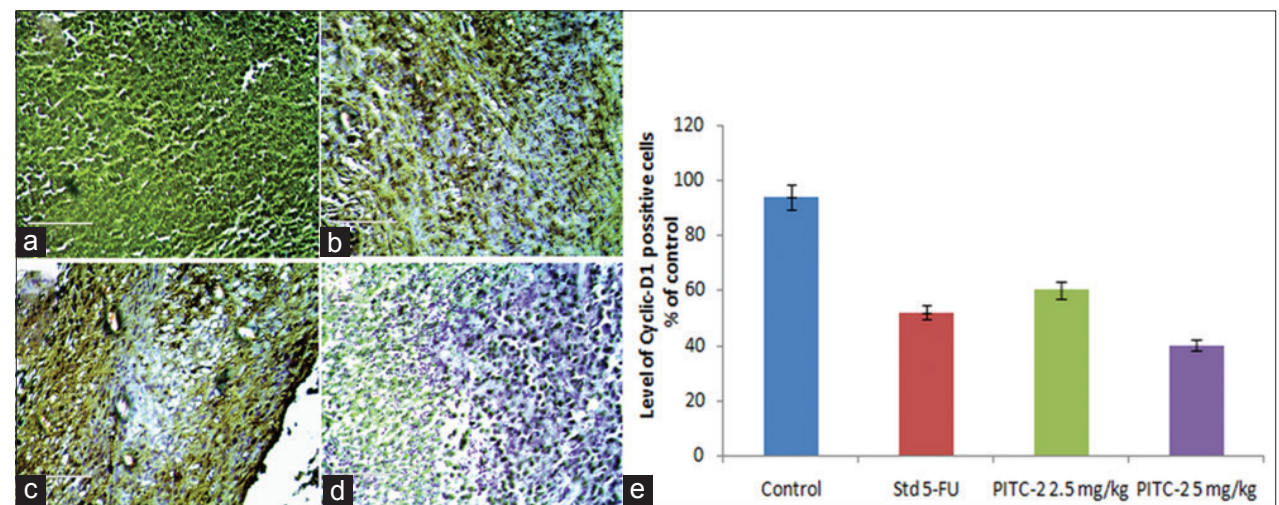

Fig. 10: (a) Sarcoma-180 control, (b) standard 5-FU, (c) PITC-2 $2.5 \mathrm{mg} / \mathrm{kg}$, and (d) PITC-2 $5 \mathrm{mg} / \mathrm{kg}$ shows cyclic-D1 expression (magnification 40×). E shows level of immunopositive cyclic-D1 cells, values are given in mean \pm standard deviation

cycle arrest through the downregulation of the intratumoral expression of Bcl-2, cyclic D1, and Ki-67 and thus highlighting antiproliferative and apoptotic properties against sarcoma-180 solid tumor model. Along with this, it shows no significant manifestation of toxic symptoms on liver and kidney of Swiss albino mice. Taking these results, we suggest that PITC-2 may be a potent prognostic factor and a potential target for tumor cells. Further investigations are in progress in our laboratory to identify the active principal and mechanisms involved in antitumor activity and to prepare a suitable formulation for modifying its way of administration.

\section{ACKNOWLEDGMENTS}

This work was supported by a grant of University Grants Commission, under the scheme "University with Potential for Excellence - Phase II," New Delhi, India.

\section{AUTHORS CONTRIBUTION}

Authors make substantial contributions in design, analysis and interpretation of data. Authors also participate in drafting the article. Authors give final approval of the version to be submitted and revised version

\section{CONFLICT OF INTEREST}

The authors declare that there are no conflicts of interest.

\section{REFERENCES}

1. Bissell MJ, Radisky D. Putting tumours in context. Nat Rev Cancer 2001;1:46-54.

2. Fattah AA, Darwish HA, Fathy N, Shouman SA. Carbition anhydrase 
inhibition boost the antitumor effect of imatinib mesylate via potentiating the antiangiogenic and antimetastatic machineries. Toxicol Appl Pharmacol 2017;316:123-38.

3. Jemal A, Siegel R, Ward E, Murray T, Xu J, Thun MJ, et al. Cancer statistics, 2007. CA Cancer J Clin 2007;57:43-66.

4. Hussein BH, Azab HA. A novel antitumor agent Ln(111) 2-thioacetate benzothiazole induces anti-angiogenic effect and cell death in cancer cell lines. Eur J Med Chem 2012;51:99-109.

5. American Cancer Society. Global Cancer Facts and Figure. $3^{\text {rd }}$ ed. Atlanta: American Cancer Society; 2015. p. 1-61.

6. Skommer J, Brittain T, Raichoudhuri S. Bcl-2 inhibits apoptosis by increasing time-to-death and intrinsic cell-to-cell variations in the mitochondrial pathway of cell death. Apoptosis 2010;15:1223-33.

7. Swanton E, Savory P, Cosulich S, Woodman P. Bcl-2 regulates caspase 3 /caspase 2 apoptotic cascade in cytosolic extracts. Oncogene 1999; $18: 1781-7$

8. Nygren P, Larsson R. Overview of the clinical efficacy of investigational anticancer drugs. J Intern Med 2003;253:46-75.

9. Nozlena SA, Ahmed AB, Rasedee A, Tengku IA, Rahman H, Keong SY. Zerumbone (ZER) induces apoptosis in HEPG2 cells via mitochondrial pathway. Int J Pharm Pharm Sci 2015;7:298-302.

10. Harborne JB. Arsenal for survival: Secondary plant products. Taxon 2000;49:435-49.

11. Pramanik KC, Biswas R, Mitra A, Bandyopadhyay D, Mishra M, Chatterjee TK. Tissue culture of the plant Pluchea indica (L.) Less. and evaluation of diuretic potential of its leaves. Orient Pharm Exp Med 2007; 7:197-204

12. Chakraborty S, Chatterjee TK. Targeting viseral leishmaniasis by mannosylated liposome incorporated PITC-2 isolated from the plant Pluchea indica (L) Less. Int J Pharm Bio Sci 2017;8:396-408.

13. Biswas R, Dutta PK, Achari B, Bandyopadhyay D, Mishra M, Pramanik KC, et al. Isolation of pure compound $\mathrm{R} / \mathrm{J} / 3$ from Pluchea indica (L.) less. And its anti-amoebic activities against entamoeba histolytica. Phytomedicine 2007;14:534-7.

14. Mutiah R, Sukardiman, Widyawaruyanti A. Cytotoxic effect of crude exteact and fraction from Calotropis gigantea leaves on human colon cancer widr cell lines. Int J Pharm Pharm Sci 2017;9:83-6.

15. Sinha A, Banerjee K, Banerjee A, Das S, Choudhuri SK. Synthesis characterisation and biological evaluation of a noble vanadium complex as a possible anticancer agent. J Organi Chem 2014;772-773:34-41.

16. Joseph MM, Aravind SR, George SK, Pillai KR, Mini S, Sreelekha TT, et al. Antitumor activity of galactoxyloglucan-gold nanoparticles against murine ascites and solid carcinoma. Colloids Surf B Biointerfaces 2014; 116:219-27.

17. Pal A, Bhattacharya I, Bhattacharya K, Mandal C, Ray M. Methylglyoxal induced activation of murine peritoneal macrophages and surface markers of T lymphocytes in sarcoma-180 bearing mice: Involvement of MAP kinase, NF-kappa beta signal transduction pathway. Mol Immunol 2009;46:2039-44.

18. Nascimento FR, Cruz GV, Pereira PV, Silva MC. Ascitic and solid
Ehrlich tumor ingibition by Chenopodium ambrosiodes L. treatment. Cell Immunol 2006;78:2650-3.

19. Chakraborty A, Talukday D, Pal A, Ray M. Immunomodulation of macrophages by methyl glyoxal conjugated with chitosan nanoparticles against sarcoma-180 tumor in mice. Cell Immunol 2014;287:27-35.

20. Bala A, Kar B, Halder PK, Bera S. Evaluation of anticancer activity of Cleome gynandra on ehrlich's ascitec carcenoma treated mice. J Ethnopharmacol 2010;129:131-4.

21. Gaballah HH, Gaber RA, Mohamed DA. Apigenin potentiates the antitumor activity of 5-FU on solid ehrlick carcinoma: Crosstalk between apoptotic and JNK mediated autophagic cell death platforms. Toxicol Appl Pharmacol 2017;316:27-35.

22. de Costa PM, de Costa MP, Jamacaru VF, Ferreira PM. Inprovement of in vivo anticancer and antiangiogenic potential of thalidomide derivatives. Chem Biol Interact 2015;239:174-83.

23. Gupta M, Mazumder UK, Kumar RS, Kumar TS. Antitumor activity and antioxidant role of bauhinia racemosa against ehrlich ascites carcinoma in swiss albino mice. Acta Pharmacol Sin 2004;25:1070-6.

24. Elsherbiny NM, Younis NN, Elseweids MM. The synergistic effect between vanillin and doxorubicin in ehrlich ascites carcinoma solid tumor and MCF-7 human brest cancer cell line. Pathol Res Pract 2016;212:767-77.

25. Torre LA, Bray F, Siegel RL, Ferlay J, Lortet-Tieulent J, Jemal A, et al. Global cancer statistics, 2012. CA Cancer J Clin 2015;65:87-108.

26. Debnath S, Karan S, Debnath M, Chatterjee TK. Poly-L-Lysine inhibits tumor angiogenesis and induces apoptosis in ehrlich ascites carcinoma and sarcoma S-180 tumor. Asian Pac J Cancer Prev 2017;18:2255-68.

27. de Sousa AP, Torres MR, Pessoa C, Lotufo LV. In vivo growth-inhibition of sarcoma 180 tumor by alginates from brown seaweed Sargassum vulgare. Carbohydr Polym 2007;69:7-13.

28. Govindarasu M, Palani M, Vaiyapuri M. In ailico docking study on kaempferitrin with diverse inflammatory and apoptotic proteins functional approach towards the colon cancer. Int J Pharm Pharm Sci 201;9:199-204.

29. Paul S, Kundu R. Induction of apoptosis by fatty acid rich fraction of Solanum nigrum on carvical cancer cell lines. Int J Pharm Pharm Sci 2017;9:199-206

30. de Silva Faria MC, dos Santos NAG, Rodrigues MA, dos Santos AC. Effect of diabetes on biodistribution, nephrotoxicity and antitumor activity of cicplatin in mice. Chem Biol Interact 2015;229:119-31.

31. Gerdes J, Lemke H, Baisch H, Wacker HH, Schwab U, Stein H. Cell cycle analysis of a cell proliferation associated human nuclear antigen defined by the monoclonal antibody Ki67. J Immunol 1984;133:1710-15.

32. Diehl JA. Cycling to cancer with cyclic D1. Cancer Biol Ther 2002;3(1):226-31.

33. Baldin V, Lukas J, Marcote MJ, Pagano M, Draette G. Cyclic D1 is a nuclear protein requires for cell cycle progression in G1. Genes Dev 1993;7:812-21. 